\title{
Report on HVAC Option Selections for a Relocatable Classroom Energy and Indoor Environmental Quality Field Study
}

Michael G. Apte, Woody W. Delp, Richard C. Diamond, Alfred T. Hodgson, Satish Kumar, Derek G. Shendell, Doug P. Sullivan, and William J. Fisk Lawrence Berkeley National Laboratory

and

Leo I. Rainer

Davis Energy Group, Inc.

October 11, 2001

Sponsored by the California Energy Commission's Public Interest R\&D Program:

High Performance Commercial Building Systems

Element 6 - Indoor Environmental Quality

Project 2.2 - Energy and IAQ Field Studies 


\section{Abstract}

It is commonly assumed that efforts to simultaneously develop energy efficient building technologies and to improve indoor environmental quality (IEQ) are unfeasible. The primary reason for this is that IEQ improvements often require additional ventilation that is costly from an energy standpoint. It is currently thought that health and productivity in work and learning environments requires adequate, if not superior, IEQ. Despite common assumptions, opportunities do exist to design building systems that provide improvements in both energy efficiency and IEQ. This report outlines the selection of a heating, ventilation, and air conditioning (HVAC) system to be used in demonstrating such an opportunity in a field study using relocatable school classrooms. Standard classrooms use a common wall mounted heat pump HVAC system. After reviewing alternative systems, a wall-mounting indirect/direct evaporative cooling system with an integral hydronic gas heating is selected. The anticipated advantages of this system include continuous ventilation of $100 \%$ outside air at or above minimum standards, projected cooling energy reductions of about $70 \%$, inexpensive gas heating, improved airborne particle filtration, and reduced peak load electricity use. Potential disadvantages include restricted climate regions and possible increases in indoor relative humidity levels under some conditions.

\section{Introduction}

The purpose of this paper is to document the selection of the high performance relocatable classroom (RC) heating, ventilation, and air conditioning (HVAC) system to be used in the California Energy Commission (CEC) funded High Performance Commercial Building Systems Element 6 field study (Task 6.2.2). The goal of this task is to demonstrate the benefits of technologies that simultaneously improve building energy efficiency and indoor environmental quality. Building designs attempting to provide such simultaneous benefits are not typically considered. A number of commercial building types could be studied for this demonstration; however, RCs are particularly well suited and topical in this era of school facilities expansion and energy efficiency concerns. An energy efficient HVAC system that can provide adequate ventilation is key to the successful implementation of such designs. The field study will be conducted in the late summer/fall of 2001 (cooling season) and the winter (heating season) of 2002.

The use of RCs in California schools has increased dramatically in recent years due to an increasing student population and state and federal class size reduction mandates. An estimated 75,000 RCs are currently in place in California schools, and the numbers are increasing at a rate of at least 10,000 per year (Waldman, 2001). The most common RC configuration is the two module 24 ' by 40 ' $\left(960 \mathrm{ft}^{2}\right)$ classroom, although a number of other styles, including a 3 module $960 \mathrm{ft}^{2}$ unit and 4 module two-story design are also used. Given the range of climatic conditions in California (CA), newly manufactured RCs must be able to supply heating, cooling and ventilation in order to meet the thermal comfort and indoor air quality (IAQ) needs of student and teacher occupants. Design cooling demands for RCs in CA climate zones range from none in coastal regions to almost 60,000 Btuh in the Central Valley. Likewise, winter design heating demands range from 18,000 Btuh on the coast to 40,000 Btuh in the mountains. 
From the standpoint of energy usage and indoor environmental quality (IEQ) the HVAC system is a critical component of the RC design. Operating costs, electric demand, and greenhouse gas reduction design constraints influence the design decisions such as equipment configuration, energy efficiency, fuel source. While the need to maintain minimum ventilation rate for removal of occupant bioeffluents and air contaminants emitted by building and classroom dictates that additional energy must be consumed for bringing in and tempering outside air. The American Society of Heating, Refrigeration, and Air-Conditioning Engineers (ASHRAE) Standard 62-1999 (ASHRAE, 1999), as well as the State of California Building Standards and Occupational Safety and Health Codes require a minimum ventilation rate of 15 CFM per person (CCR, 1995; CCR, Title 8 ) in nonresidential buildings.

The standard RC currently shipped to schools includes an all-electric compressor-based wall-mounted HVAC system, typically with two or three ducted supply ceiling diffusers and a direct return through the wall. The wall mount heat pump used in RCs are typically rated from 3.5 to 5 tons depending upon the anticipated demand. Most of the systems currently sold have cooling efficiencies of 10 SEER, however, specification of a 12 SEER wall mount unit is becoming more common (for example the Los Angeles Unified School District (LAUSD) specifies a 12 SEER HVAC package for all new RCs). Heating from these units is provided by both the heat pump and 5 to $15 \mathrm{KW}$ of electric strip heat for pick-up depending upon the model. Air distribution is typically provided via a supply plenum attached to the wall mounted HVAC unit, either internal to the back wall or into the ceiling. The two or three insulated flex-ducts are connected to the plenum and supply ceiling diffusers in a T-bar ceiling.

Ventilation air from outside the $\mathrm{RC}$ is dependent on mechanical ventilation from the HVAC system since window and door use for natural ventilation is often unfeasible due to school rules and noise control needs. Most wall mount HVAC units are equipped with a movable damper that can be set to provide up to $25 \%$ of the delivered supply from outside air. With the damper in full open position, the fan can provide ventilation sufficient for about 30 occupants. However, in practice the actual amount of outside air that is delivered to the classroom is often less for a two key reasons. First, the systems only provide ventilation when their fan is turned on - this occurs either when the teacher manually turns the fan on, or when the HVAC system cycles on for heating or cooling. Second, in many instances the outside air damper is adjusted to a lower percentage of outside air in order to save energy, or by mistake, since commissioning is required - the HVAC systems are typically shipped from the manufacturer with the dampers set in the fully closed position. These conditions suggest that it is likely that many RCs are not providing adequate, continuous ventilation air to their occupants.

Additional RC HVAC characteristics that can affect IEQ are the level of mechanical noise and the efficacy of the supply air filtration. There is a lot of anecdotal evidence that existing wall mount HVAC systems in RCs are excessively noisy due to a combination of loud compressors and fan cycling. When HVAC units are too loud the teachers may turn them off in order to limit background noise. This reaction to noise causes a deficit in ventilation and hence poor air quality in the classroom. The teacher is caught between meeting ventilation and space conditioning needs and having the quiet environment necessary for learning. 
Filtration is necessary to ensure that particulate matter (PM) concentrations in the ventilation air are low. Without adequate inlet filtration airborne PM from outdoors will be entrained into ventilation air. Standard filtration supplied by the conventional HVAC systems for RCs is minimal. Improved supply air filtration can benefit the IEQ of RCs, especially in areas with elevated outdoor PM concentrations.

\section{Available HVAC options}

\section{Cooling}

Although a range of HVAC system types could be used to meet the conditioning and ventilation needs of the $\mathrm{RC}$, few available systems are significantly more energy efficient than the wall mount system currently available. Furthermore, the modular and transportable nature of the RC restricts the design choices to wall mountable systems since issues such as road clearance and additional costs of field installation dictate placement of the equipment.

Although some slightly more energy efficient compressor-based systems exist, the potential increases in RC energy efficiency to be gained by use of this type of technology is at most $30 \%$ (some 13 SEER systems are on the horizon) compared to the 10 SEER wall mount systems currently employed. An example of a more efficient system currently available is the 12 SEER RC HVAC units specified by the LAUSD. Split systems (compressor mounted separate from air handler) are not a viable option as the compressor would have to be mounted on a separate external pad taking up more room and requiring significant additional installation labor.

One practical technology suitable for mechanical cooling of RCs is evaporative cooling, or hybrid evaporative-compressor systems. Existing evaporative cooling technologies that are reasonably mature include direct evaporative systems (i.e., "swamp coolers"), indirect evaporative coolers that employ a heat exchanger to isolate the evaporative process from the ventilation supply air, and the indirect-direct evaporative systems which cool the supply air in two stages. The overall energy benefits of evaporative cooling lie in the elimination of the energy used for compression of the cooling fluid, as the only energy use consists of fan power for moving the air and a small amount of pump power to wet the media. Typical energy savings for evaporative cooling can be on the order of 50 to $75 \%$ of the amount used by standard compressor type air conditioners. A disadvantage of direct evaporative cooling, particularly in California where ambient relative humidity $(\mathrm{RH})$ in many climatic regions is moderate, is that the saturated supply air causes an increase in indoor humidity levels. This can lead to growth of opportunistic microbiological contaminants in the system or in the conditioned space. Humidity is not a problem with indirect evaporative systems, however the low efficiency of indirect heat exchangers results in lower energy savings. Indirect-direct evaporative coolers (IDEC) use a combination of these two systems to provide lower humidity air at a higher efficiency than direct units. Supply air is first drawn though the indirect stage, cooling it without adding any moisture. Then, the cool, dry air is drawn through the direct stage which cools the air more while adding a small amount of moisture due to the lower moisture capacity of the cool air. An additional benefit of the IDEC is that it is relatively quiet compared to conventional HVAC systems, as it does not use a compressor. Hybrid evaporative-compressor systems are an attractive approach with the potential for 
significant energy savings, however such systems are a recent development and not a mature technology suited for this study.

\section{Heating}

In California the heating load dominates RC HVAC energy use, making the heating system selection important from an energy efficiency standpoint. The RC heating technology options are greater than those for cooling. Conventional available energy sources for heating include electricity, natural gas, and liquefied petroleum gas (LPG). Most school district ordinances prohibit the use of LPG stored onsite at schools, however some rural schools have variances to allow for siting of LPG tanks on school premises. Electricity is supplied to all RCs in California and as such is the most common source of heating energy. However the use of electricity for resistance heating is very costly and demanding on state energy resources. Currently (July 2001) gas costs are also high, and due to price caps on electricity are a less attractive alternative than usual, however this condition will certainly be reversed in the long-term as the California energy market normalizes.

Electric powered heating systems available for the $\mathrm{RC}$ markets are either the wall mount compressor based systems that operate in a heat pump mode and have an electric resistance strip heater for pick-up (overall coefficient of performance (COP) of about 2.0 for a 10 SEER wall mount), or electric strip or baseboard heating (COP of 1). An alternative to these conventional electric heaters is radiant electric ceiling panels that fit in the RC T-bar ceiling grid. These radiant heaters have an effective COP of about 1.25 (at best) since the radiant heating warms room surfaces rather than surrounding air allowing lower settings to achieve the same thermal comfort level.

Gas powered heating options include a hybrid wall mount air conditioning unit with an integral gas furnace, and standard wall or packaged gas furnaces. The hybrid "gas-pack" systems are relatively new and their market penetration is unknown but is estimated to be less than $20 \%$ of the market. Wall mounted and packaged gas furnaces are employed for heating in some older RCs and have been observed as the only form of space conditioning in some Los Angeles county RCs. Although no known accidents have occurred in California, vented gas furnaces have the potential to malfunction causing a buildup of toxic combustion gases indoors. Gas furnaces are not common in new RCs.

Another gas heat option is hydronic forced air, a system not been employed to date in RCs. This system uses an outdoor wall-mounted $85 \%$ efficient instantaneous natural gas water heater and a heating coil mounted in the air distribution plenum shared with the cooling system air handler. A small electric circulation pump is used to circulate hot water through the heating coil. This design incorporates the cost effectiveness of gas fuel and the safety of having the combustion device separated from the supply air. Heat output of this system can be supplied at rates as high as $80 \mathrm{kBtuh}$ or more.

\section{Air supply and distribution}

The current generation of mechanically ventilated RCs typically makes use of a supply plenum with two or three ducts and supply diffusers set in a T-bar ceiling. The return air is collected at a single wall register integral with the wall mounted packaged HVAC 
system. The attic space is passively connected to the occupied room space and is not used as a plenum.

The standard packaged HVAC systems are supplied with an adjustable outside air damper that can be set to provide up to $25 \%$ outside air in the supply stream. This damper is supposed to be set upon installation to meet the outside air needs of the RC based upon its projected occupancy. It is also supposed to be readjusted if the class occupancy changes. Optional outside air dampers with mechanically actuated settings for up to $50 \%$ outside are available for wall mount HVAC systems and are becoming more popular.

Displacement ventilation (DV) is an alternative air distribution design where floor-level displacement supply air diffusers are used to create an upward displacement (piston-like) indoor airflow. This type of distribution system can provide improved ventilation effectiveness since fresh ventilation air mixes less with contaminated aged room air. DV requires less outside air to meet the same removal rate of indoor contaminants and therefore less energy is needed to for conditioning ventilation air.

The conventional HVAC systems installed in RCs are designed to supply outside air only when the air handler is turned on. This condition only occurs when there is a heating or cooling demand, or when the thermostat is manually set to the "Fan On" setting. In contrast, continuous ventilation (CV) systems are designed to provide a continuous flow of outside air at a rate greater than or equal to the ASHRAE Standard 62-99 minimum ventilation standard level. The purpose of a CV system is to ensure that the minimum ventilation is met, however the penalty for providing adequate outside air is that it must be conditioned. Installation of $\mathrm{CV}$ systems with energy efficient air handler fans and heating and cooling systems can be attractive if they replace lower efficiency conventional systems without $\mathrm{CV}$. One advantage of the IDEC is that it is designed to provide CV using 100\% outside air.

Some school districts and Office of Public School Construction (OPSC) have begun to require carbon dioxide $\left(\mathrm{CO}_{2}\right)$ sensors to control the ventilation rate. The underlying approach of these systems is to assume that occupancy is the only significant source of indoor air contamination. Occupant generated $\mathrm{CO}_{2}$ is used to trigger the opening of an outside air damper when a particular concentration setpoint is exceeded (e.g. 800 parts per million $\mathrm{CO}_{2}$ ). Although such systems are likely to provide improved IEQ there are many cases where pollutants generated from indoor activities and emissions from building materials may degrade the quality of classroom air without reaching the $\mathrm{CO}_{2}$ threshold necessary to supply outside air.

\section{Filtration}

Filtration of supply air is important for the IAQ of the RC, especially at sites with poor outdoor air quality and high particulate levels. Recent research at LBNL indicates that filters with an ASHRAE standard 52-76 (ASHRAE,1992) Dust Spot Efficiency (DSE) rating of $45 \%$ or lower are not effective for reducing indoor concentrations of outdoor fine-mode and environmental tobacco smoke particles, and those with DSE ratings above $85 \%$ only provide incremental increases in benefit (Fisk and Faulkner, 2001). Although 
improved efficiency filters are available for RC HVAC systems, they are less commonly employed than low quality filters that are considerably less expensive. Typically, oneinch fiberglass filter media are supplied with RC HVAC equipment. These standard filters have a $10 \%$ DSE rating. At additional cost, two-inch pleated filters with ratings of $35 \%$ to $55 \%$ efficiency are available for the standard HVAC systems, however these filters are not commonly specified for use in RCs. For example, the OPSC RC specification (OPSC, 2000) requires a 1" filter and does not specify minimum filtration efficiency.

The OPSC specification requires that the standard RC HVAC filters be replaced monthly. $\mathrm{RC}$ filter replacement requires that trained facilities personnel or a contractor visit each $\mathrm{RC}$ at each school in a district to remove the old media and replace it. This task amounts to a considerable amount of labor over a school year if the filter replacement must be conducted on a monthly basis. By selecting a higher capacity filter the frequency of replacements can be reduced substantially. However, filters should not be replaced less frequently than annually since the accumulation of odors and biological materials could affect the quality of HVAC supply air and the added pressure drop will reduce supply airflow. By trading the labor costs associated with filter replacements off for a higher quality filter system, filtration with greater DSE can be provided.

\section{Selected system}

The selection of the advanced HVAC system for Element 6 was based upon a number of factors. Energy efficiency and adequate ventilation were the highest priority. Selecting system that could provide reduced peak-load heating and cooling demand was also a strong factor, as was a design that minimizes emissions of greenhouse gases. The ability to effectively filter the outdoor supply air was also important. Finally, it was necessary that the design be compatible with existing RC structures and suitably quiet for a classroom environment.

The original Element 6 proposal presented two HVAC study components; a market transformation (MT) component (was to be simultaneously funded by PG\&E via a separate contract process) and a research component which was to be funded by CEC. Table 1 presents the original concept for HVAC selection. Package A was to be the MT component system while Package B was to be developed for the CEC research. The original Package A design was a system promoted by PG\&E in their Premium Efficient Relocatable Classroom (PERC) program (DEG, 2000). Note that Package A, consistent with the PERC design, specified the use of Radiant Electric ceiling panels as the means to provide heating for the RCs.

After a review of the options for RC HVAC discussed above, the IDEC continued to be the primary choice for the advanced HVAC option. However, a number of issues came into play in the final HVAC equipment selection, as follows. The proposal was written based upon the assumption that the IDEC was a mature and available product on the market, suitable for the MT effort. Indeed, at the time that the proposal was written, Smart Cool, Inc. (Sacramento, CA) marketed the IDEC, primarily for the residential sector. This product was ideally suited as a MT demonstration project. Unfortunately, Smart Cool, Inc. went out of business, leaving a small inventory of IDEC units. With this situation at hand, it was decided that the IDEC was not as ready for MT as originally 
assumed, and more suited for a research project as the advanced cooling system in Package B. A new MT project was proposed to PG\&E that would demonstrate the value of utilizing a continuous ventilation strategy with conventional 12-SEER wall mount HVAC systems.

Thus, the IDEC became the air conditioning system of choice for Package B research. This selection eliminated the design and testing of a DV system for RCs as it would be impossible in a small study of four RCs to discern the relative contributions of the IDEC and DV to energy and IEQ improvements. A filtration component as outlined in Option 2 of Package B was selected for part of the advanced HVAC system.

The PERC specification of radiant electric ceiling panels for heating came under scrutiny as the 2001 California energy crisis loomed. Electric resistance heating is very expensive and demanding on the winter peak daytime load. Furthermore, due to generation and power line inefficiencies electric resistance heating end use efficiency and greenhouse gas emissions are necessarily higher than efficient natural gas combustion heating systems.

With electric radiant heating the IDEC-based HVAC package has a net annual efficiency lower than the heat pump systems. This is because of the combined facts that: (a) in California the heating load dominates the HVAC energy use of RCs, and (b) the radiant electric panels have a COP of about 1.25 (at best) when used in RCs (compared to a COP of about 2.0 for a 10 SEER heat pump with a strip heater).

With these issues at stake an efficient natural gas-based hydronic heating system was selected. This system parallels the "gas pack" hybrid compressor air conditioning/gas furnace heating technology available in CA for use on RCs and other small commercial structures. Although efficient, this selection is not without drawbacks, and cannot be expected to be applicable to all situations. Drawbacks include poor access to natural gas distribution lines and the potential high cost of trenching gas lines at existing RC sites. The natural gas option is most likely to provide a payoff in new installations where the cost of trenching and installation of gas lines can be shared among a number of RCs sited together and the gas lines can be installed at the same time as electricity and water lines.

\section{Description of IDEC with hydronic heat}

With all of the options weighed, an integrated HVAC system incorporating the IDEC for cooling and a natural gas-fired hydronic heating system was selected. The IDEC units to be used in the study are unused stock manufactured by Smart Cool, Inc. These units contain an efficient, 1-horsepower electronically commutated variable speed motor, designed to provide a total flow of 0 to 2000 CFM. The air stream taken from outdoors enters the IDEC fan and is split between a supply air side and an indirect evaporative cooling side of a water-wetted heat exchanger. The supply airflow rate varies from a minimum value set to provide 15 CFM per occupant (e.g. 315 CFM for a classroom of 20 students and one teacher), to a maximum of approximately $1600 \mathrm{CFM}$ under full cooling conditions.

The IDEC discharges into an attic mounted plenum which contains a $14 \times 41$ " hydronicheating coil. An $85 \%$ efficient natural gas fired instantaneous water heater, and a 
hydronic circulating pump which supplies four gpm of water to the heating coil (see Figure 1). The pump is controlled by a signal from the IDEC control board. The water heater maintains a water temperature of $150^{\circ} \mathrm{F}$ whenever the pump is circulating water. The system supplies heated air through the IDEC duct system, while maintaining outside air flow of 15 CFM per RC occupant. A pick-up heating mode is incorporated into the controller in order to ensure rapid heating of the RC during initial heating such as morning times. During this period the IDEC controller increases the supply flow to 700 CFM to extract more heat from the heating coil. This is analogous to the electric strip heater in the conventional compressor-based RC HVAC systems. A set of current working drawings for the installation RC HVAC system are included in Appendix A.

\section{Hydronic heating system development and testing}

A prototype IDEC/hydronic HVAC system was constructed at LBNL for the purpose of testing the hydronic heating system. The system components are listed in Table 2. This system was installed in an LBNL trailer (Building 67C) similar in size and shape (24' $\mathrm{x}$ $50^{\prime} \times 8^{\prime}$ ) to a typical RC. B67C differs from a RC in that it is less insulated, contains much more thermal mass (a lot of heavy equipment is stored inside), and is 10' longer and the ceiling is 6" lower. Photographs documenting the B67C IDEC/Hydronic setup are shown in Appendix B. The IDEC and instantaneous water heater were mounted on an exterior wall of the trailer and the plenum was connected to the IDEC through a boarded off window opening. The hydronic heating plumbing was passed through the sealed window opening as well. All hydronic plumbing was covered with foam pipe insulation. The system was operated over a six-day period. Indoor temperature results for this period can be seen in Figure 2. The IDEC temperature controller appears to have been able to maintain the indoor temperature as set.

The actual temperature setting on the IDEC controller was probably slightly lower (approximately $66^{\circ} \mathrm{F}$ ) than would be desired in the Element $6 \mathrm{RCs}$, however the hydronic heating system should have no problem supplying heat at that temperature. It can be seen during the third day of the test the indoor temperature was allowed to drop when the heating system was turned off. The elapsed recovery time to reach the temperature setpoint in B67C after the system was turned back on was about five hours. Clearly, this duration would be unacceptable in a RC. However, there are three reasons that it is not expected that the temperature recovery time will be as long in the RCs. The reasons are (1) the extremely high thermal mass of B67C due to stored equipment would not be typical of the RC; (2) B67C has significantly less insulation than the RCs; and (3) during these tests, the IDEC controller had not been programmed to have a "pickup" mode to supply more heat during such heat-up periods.

\section{Sizing - heating and cooling}

A spreadsheet was developed (at Davis Energy Group) as an aid to predict heating and cooling loads and design parameters for the IDEC/hydronic heat combination in climate zones across California. Figure 3 shows a typical screen of the Modular Classroom Heating Sizing Worksheet used to estimate the heating requirements for the hydronic heating system. This worksheet uses the RC structural design and internal, solar, and ventilation loads as well as climate data to estimate maximal heating loads. 
Figure 4 shows a typical screen for the Modular Classroom IDEC Sizing Worksheet. Again, the RC structural design and internal, solar, and ventilation loads as well as climate data are used to estimate maximal cooling loads. However, in the case of this worksheet the IDEC capacity is estimated based upon climatic humidity data and a prediction of the acceptability of thermal comfort in the RC is made using the ASHRAE method (ASHRAE, 1992).

\section{Distribution system and relief}

Figure A1 depicts the placement of the IDEC and associated distribution in the study RCs. The IDEC is mounted on the back wall of the $\mathrm{RC}$ with a discharge opening framed through the wall. A supply plenum is attached at ceiling height on the inside of this framed opening. The supply plenum is shaped to transition into a 14 " high by 41 " wide enclosure within the RC ceiling. Three 12" round duct collar transitions provide connection to insulated 12" flexible ducts. These ducts supply air to three supply registers distributed evenly along the 40' length of the RC. The supply registers were selected to have adequate throw of supply air throughout the operating flow range of 100 to 530 CFM that is distributed to each register. Two 14" square gravity relief dampers are installed in the front wall of the $\mathrm{RC}$ to prevent pressurization of the structure.

\section{Controls}

The IDEC control system is designed to have four modes: Off, Auto, Heat Only, and Cool Only. Except when turned off, the IDEC system will continuously supply a minimum of 315 CFM of outside air to the classroom of 21 occupants (a technician can adjust this minimum flow for other nominal occupancies). In Auto mode the system automatically switches between heating and cooling, with an optimized band of 5 degrees between heating and cooling where it does neither. In Heat mode the system is designed to provide requested heat in a setpoint ranging from approximately 60 to $70{ }^{\circ} \mathrm{F}$, with a deadband of $\pm 2{ }^{\circ} \mathrm{F}$. The IDEC controller employs a duct sensor to monitor supply air temperature and supply heat whenever it is below $55^{\circ} \mathrm{F}$. In Cool mode the IDEC controller is designed to supply cooling in a setpoint range of approximately 70 to $80^{\circ} \mathrm{F}$, however the lower limit is dictated by the capacity of the IDEC and ambient conditions. A heating pickup mode which doubles supply flow during initial heating is incorporated into the controller software in order to ensure comfort during morning hours.

\section{Filtration}

As discussed above, filtration of HVAC supply air is necessary for removal of particulate matter that would otherwise contaminate the $\mathrm{RC}$ environment. In the case of the IDEC/hydronic system it was necessary to identify a practical particle filtration system that would meet the particle removal goals without negatively impacting the airflow of the IDEC air handler. In order to maintain sufficient cooling effectiveness the IDEC total supply flow should remain above about 1400 CFM.

A series of experiments were run to develop an inlet filtration system for the IDEC. The results of these experiments are shown in Figure 5. The first curve (diamonds) depicts the results of layering wire mesh over the IDEC air inlet (bottom of IDEC) and monitoring the inlet pressure drop and supply airflow (sum of diffuser flows). 
With the results of this response curve as input the filter products literature was used to select the best choice of filter media. Table 3 lists a range of filter products that are available for inlet air filtration. The products in bold meet the $65 \%$ dust spot efficiency rating desired for adequate filtration. Table 3 also provides information on filter depth (the deeper the filter the less pressure drop and greater particle holding capacity), filter cost, the predicted average fan power that the filter would require, the filter dust holding capacity, and filter costs (based upon estimated average outdoor particle concentrations, filter life, and weekly energy use) associated with the various models. These estimates are based upon inlet airflow of 2000 CFM (maximum IDEC cooling flow) for 50 hours per week. Thus these cost and filter life estimates are conservative since the IDEC operates at lower flow rates except during maximum cooling periods. During most heating and all non-cooling periods the IDEC operates at only 315 CFM.

Based upon the alternatives shown in Table 3 the Koch DuraMax filter media was selected for use in the Element 6 field study. This selection was based upon a need for low inlet pressure drop and high capacity. The IDEC/hydronic system, including plenum, heating coil, ducts and diffusers was tested with $7.3 \mathrm{ft}^{2}$ of Koch DuraMax filter media installed in a "u-shape" filter rack at the IDEC air inlet. The second curve in Figure 5 (circles) shows the response of IDEC flow to additional filter loading a using this configuration. The results indicated that the "u-shape" filter rack was considerably more restrictive than expected - this was likely due to the shape of the IDEC air inlet as well as internal turbulence due to the opposing air streams caused by the filter rack design. Thu, an alternative inlet configuration for the filters was sought to maximize IDEC airflow rate.

The IDEC case is designed with a cover plate placed directly over the inlet to the IDEC fan on each side. An alternative filter rack was designed in which a 12" x 24" DuraMax filter was mounted at each of these side inlet ports, and a 20 " x 24 " filter was installed at the main IDEC inlet. The third curve in Figure 5 (triangles) represents the flow vs. pressure drop of the IDEC with this filter configuration. Note that the initial flow is greater in this case with filters attached than in the initial tests without filters before the IDEC sides were opened. This final curve indicates that the IDEC flow should be optimal until the filters load to a pressure drop of about $125 \mathrm{pa}$.

Based upon these tests, Table 3 indicates that the Koch DuraMax filter would take several years before it became unacceptably loaded. Assuming that the filters were to be replaced on a yearly basis the weekly cost per occupant for the $65 \%$ DSE filtration would be about $\$ 0.16$. At full IDEC flow these filters would require about 0.14 horsepower to operate. Although the DuraMax filter was selected, it is possible that other less expensive 65\% DSE filters could be used as well. For example the Koch Multiflow Series $\mathrm{G}$ with a weekly cost of $\$ 0.08$ per occupant might be acceptable.

\section{Summary}

After reviewing the available alternatives, a high-performance RC HVAC system for Element 6 of the CEC High Performance Commercial Buildings Systems Program was selected. This system incorporates a highly efficient indirect/direct evaporative cooler and gas hydronic heating system. A $65 \%$ efficient inlet filtration system was designed, tested, and prepared for use in the field. This prototype HVAC system will be installed 
on four RCs for field-testing during 8-10 weeks in the late summer/fall of 2001 (cooling season) and in the winter (heating season) of 2002.

\section{Acknowledgements}

This study was sponsored by the California Energy Commission through the Public Interest Energy Research program as Element 6.2.2 of the Lawrence Berkeley National Laboratory High Performance Commercial Buildings Systems research CEC Contract Number 400-99-012. The study was additionally supported by the U.S. Department of Energy under Lawrence Berkeley National Laboratory contract number DE-AC0376SF00098. We would like to thank Simon Allard for his photographs of the hydronic test setup, and David Faulkner of LBNL for his review of this manuscript.

\section{References}

ASHRAE (1992) Gravimetric and dust-spot procedures for testing air cleaning devices used in general ventilation for removing particulate matter, ANSI/ASHRAE Standard 52.1, American Society of Heating, Refrigerating, and Air Conditioning Engineers. Atlanta.

ASHRAE (1992) Thermal Environmental Conditions for Human Occupancy, Atlanta, GA, American Society of Heating, Refrigerating, and Air Conditioning Engineers (ANSI/ASHRAE Standard 55-1992).

ASHRAE (1999) Ventilation for acceptable indoor air quality, Atlanta, GA, American Society of Heating, Refrigerating, and Air Conditioning Engineers (ASHRAE Standard 62-1999).

CCR, CA Code and Regulations Title 24, Part 6. Energy efficiency standards for residential \& nonresidential buildings, July 1995.

CCR, CA Code and Regulations Title 8 \$5142 \& Title $24 \S 121(\mathrm{c})$. Operation \& control requirement for minimum quantities of outdoor air.

DEG (2000) Premium Efficiency Relocatable Classroom Performance Assessment in $P G \& E$ Territory, PG\&E Internal Report from Davis Energy Group dated 12/29/2000, PG\&E Project Manager Larry Stevens, Pacific Gas and Electric Company, San Francisco, CA.

W.J Fisk and D. Faulkner (2001) Performance and cost of particle air filtration technologies, Earnest Orlando Lawrence Berkeley National Laboratory, Berkeley, CA, 94720. LBNL-47833.

OPSC (2000) Bid Specification for Prefabricated Relocatable Classroom Buildings (General Requirements), California Office of Public School Construction, \#5410-0BS028, November 2000 
Waldman (2001) Personal Communication with Jed Waldman, California Department of Health Services, Indoor Air Branch, June 6, 2001. 


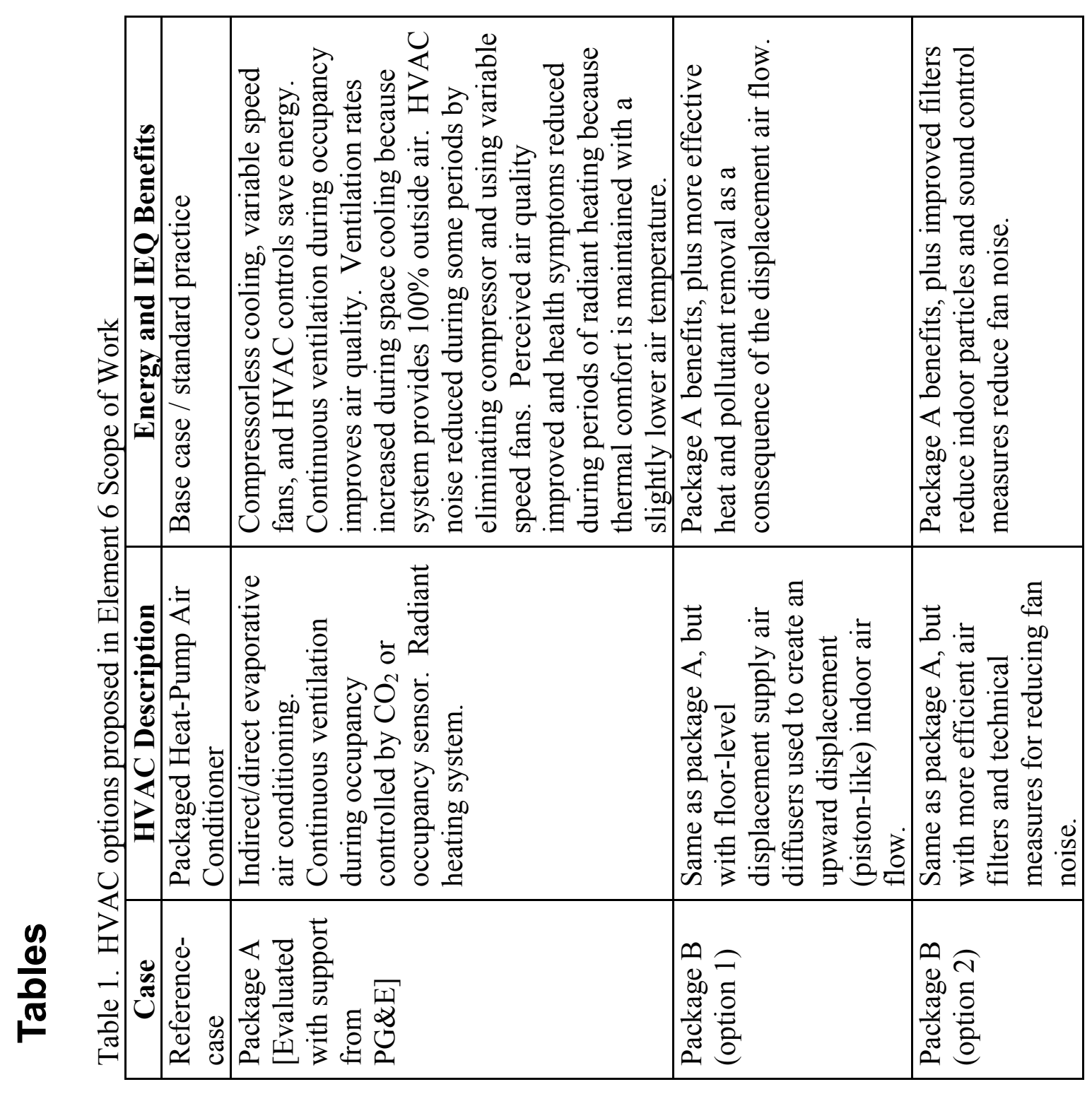




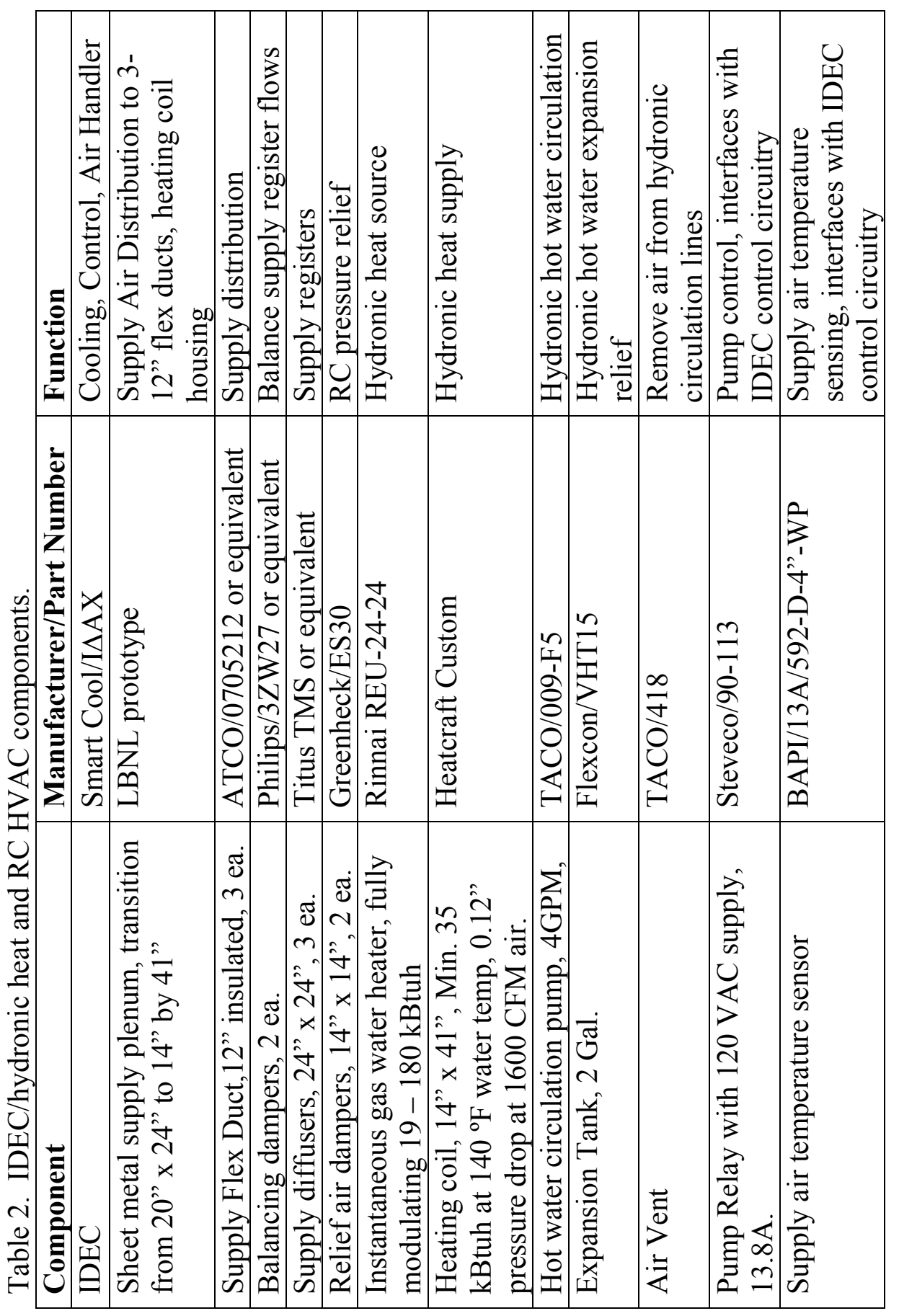




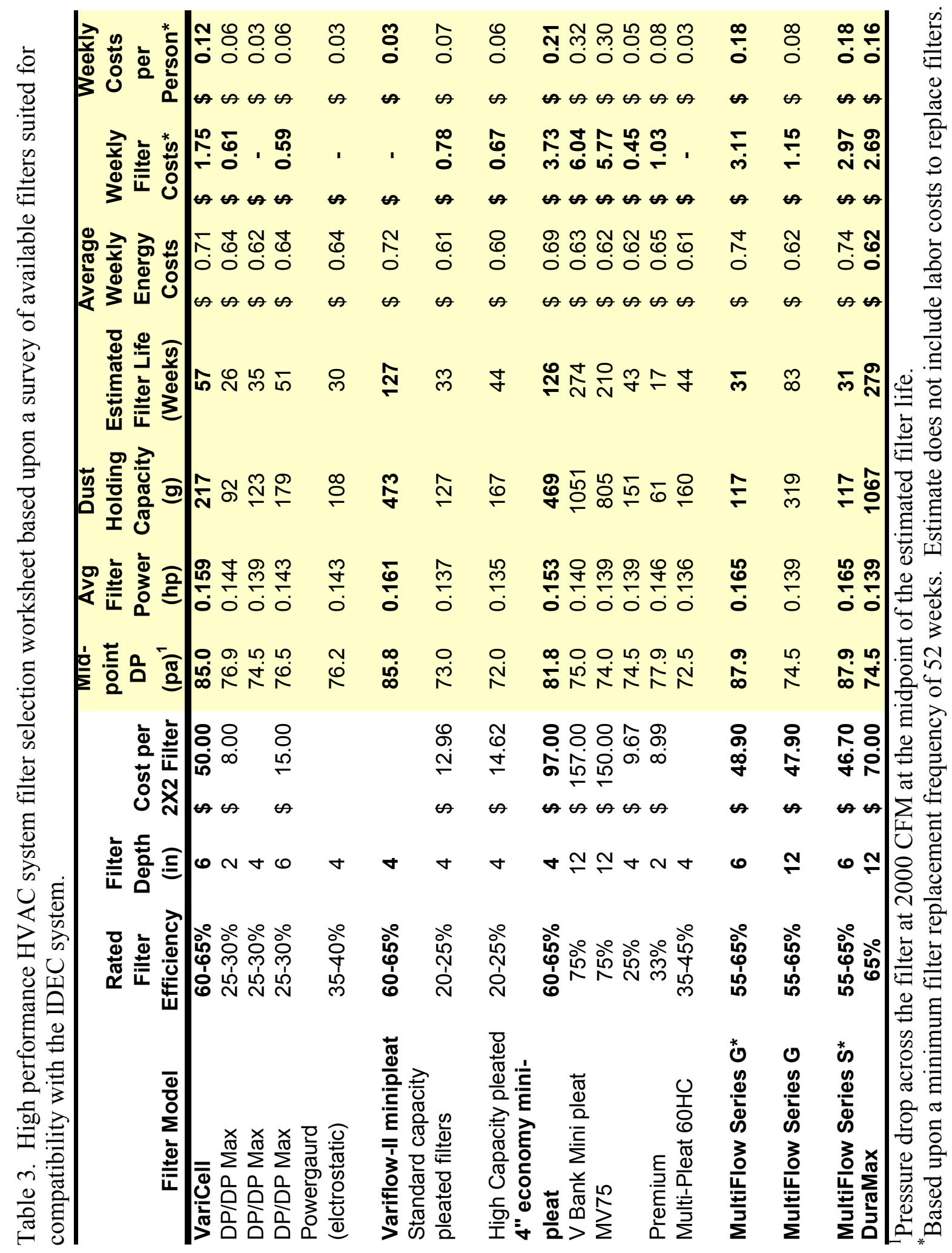




\section{Figures}

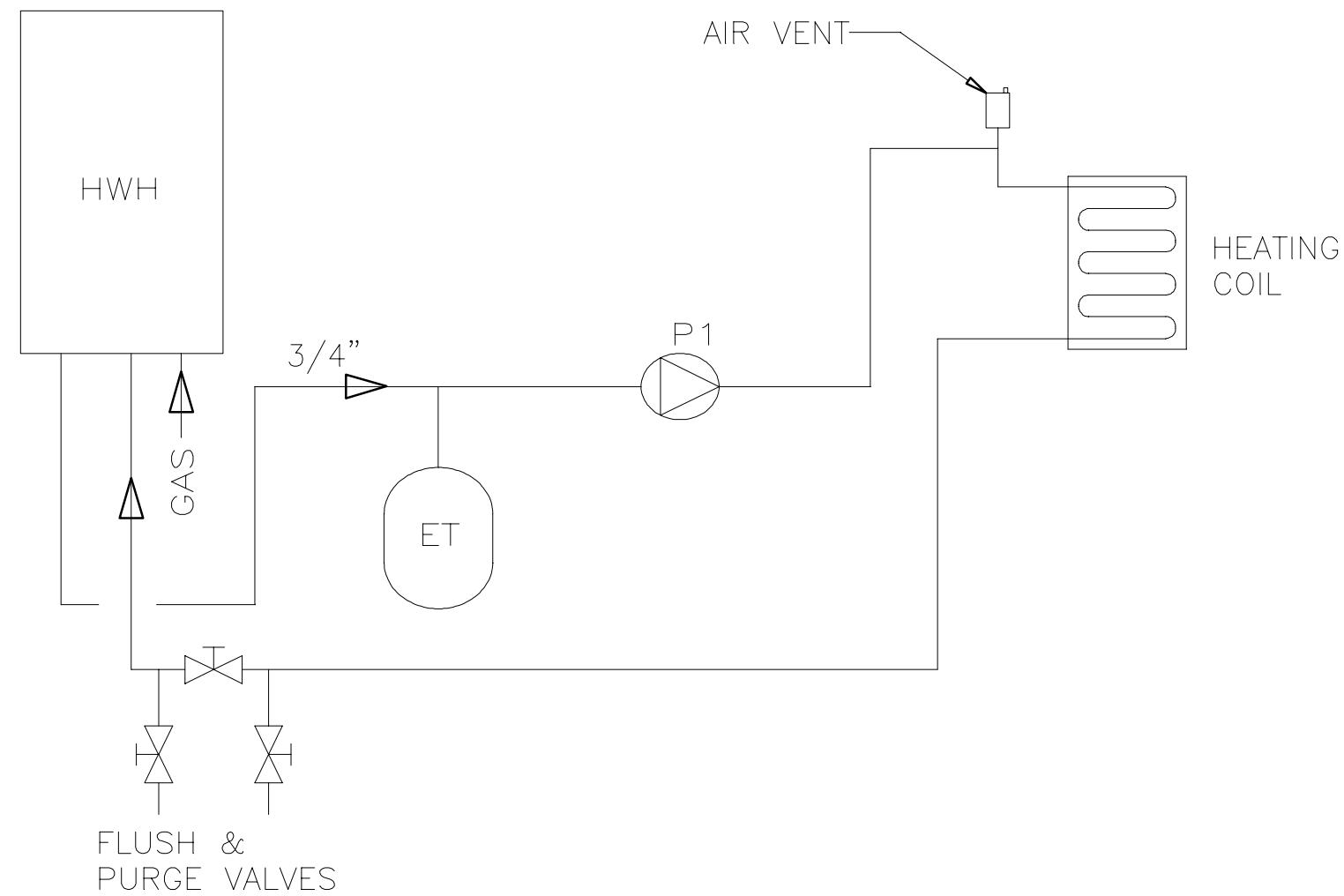

Figure 1. Hydronic heating system for IDEC. HWH is a variable output (19- 180 kBtuh) instantaneous gas-fired hot water heater. P1 is a hot water circulation pump. Heating Coil is installed in the IDEC plenum. 

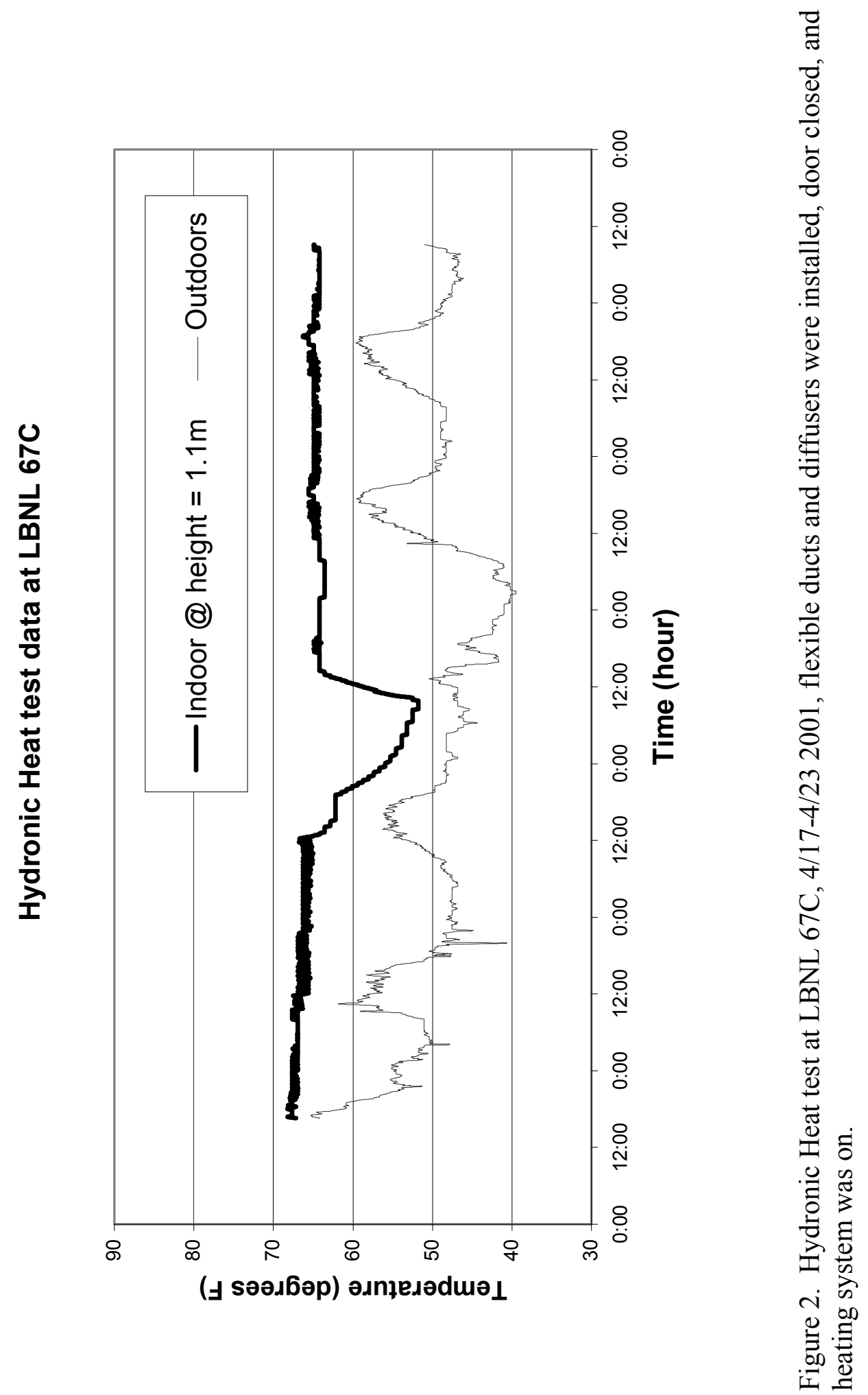


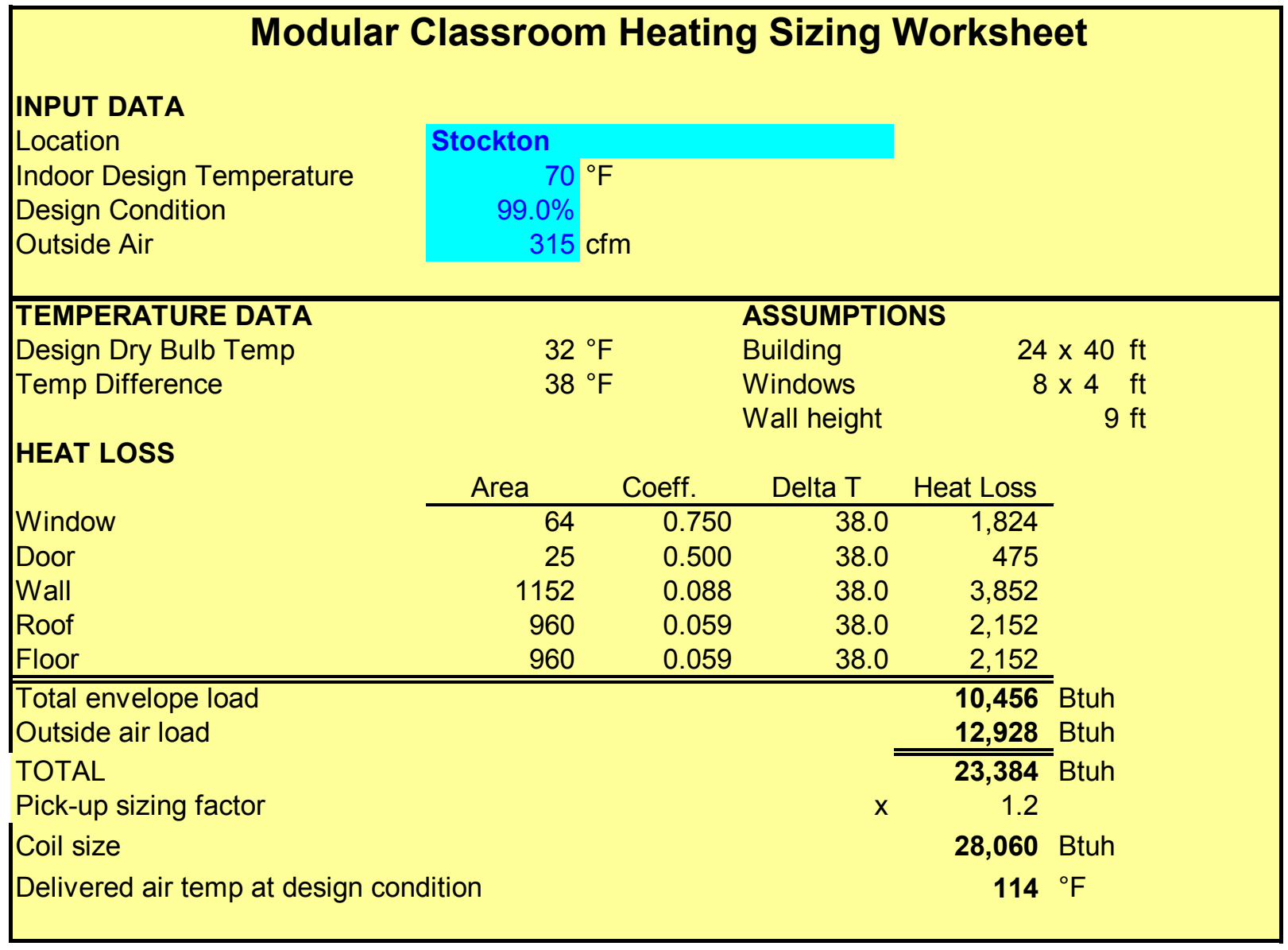

Figure 3. Modular Classroom Heating Sizing Worksheet for California Climate Zones (Note to readers of the electronic version of this file - the parameters and results of this worksheet can be explored by double-clicking within its borders). 


\section{Modular Classroom IDEC Sizing Worksheet}

\section{INPUT DATA}

Location

Indoor Design Temperature

Design Condition

No of Students

IDEC effectiveness

Static pressure

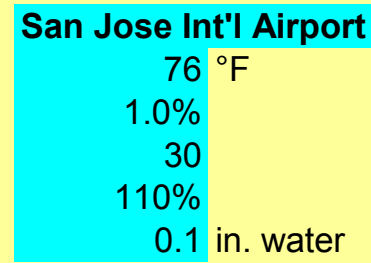

0.1 in. water

\section{TEMPERATURE DATA}

Design Wet Bulb Temp

Mean Coincident Dry Bulb Temp (

Daily Temp. Range

Temp Difference

$\begin{aligned} 68{ }^{\circ} \mathrm{F} & \text { ASSUMPTIONS } \\ 85^{\circ} \mathrm{F} & \text { Building } \\ 22.3^{\circ} \mathrm{F} & \text { Windows } \\ 9^{\circ} \mathrm{F} & \text { Wall height } \\ & \text { People (sensible) } \\ & \text { Equipment }\end{aligned}$

$24 \times 40 \mathrm{ft}$

$8 \times 4 \mathrm{ft}$

$9 \mathrm{ft}$

200 Btuh/person 600 Watts

\section{HEAT GAIN}

Glass Solar

Glass Conduction

Door Conduction

Wall Conduction

Roof Conduction

People

Equipment

\begin{tabular}{rrrr}
\multicolumn{1}{l}{ Area } & Coeff. & \multicolumn{1}{c}{ Factor } & Heat Gain \\
\hline 64 & 0.370 & 73.0 & 1,729 \\
64 & 0.750 & 9.0 & 432 \\
23 & 0.500 & 9.0 & 105 \\
1152 & 0.088 & 12.6 & 1,277 \\
960 & 0.035 & 33.0 & 1,109 \\
& & & 6,000 \\
& & & 2,048
\end{tabular}

Total Cooling Load

2,048

\section{IDEC CAPACITY}

IDAC Air Flow Rate

Delivery air temperature

Total Capacity

IDEC meets load?

$$
\begin{aligned}
1,690 & \text { CFM } \\
66.3 & { }^{\circ} \mathrm{F} \\
17,704 & \text { Btuh } \\
\text { Yes } &
\end{aligned}
$$

\section{INDOOR CONDITIONS}

Sensible/Total ratio

0.74

Dew Point

$63.1^{\circ} \mathrm{F}$

Relative Humidity

$64 \%$

Wet Bulb

In ASHRAE Summer Comfort Box?

Yes

Figure 4. Modular Classroom IEDC Sizing Worksheet (Note to readers of the electronic version of this file - the parameters and results of this worksheet can be explored by doubleclicking within its borders). 


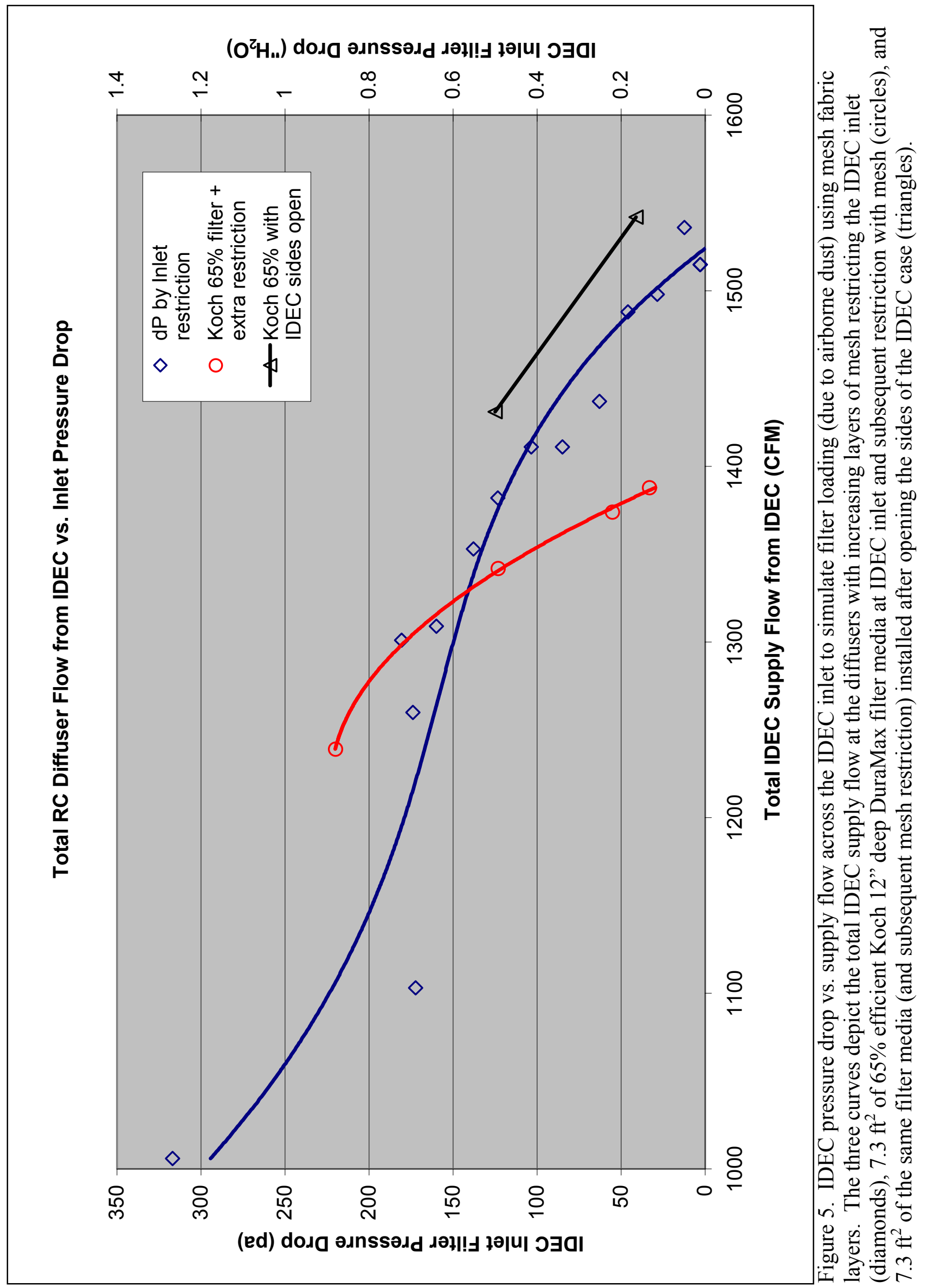




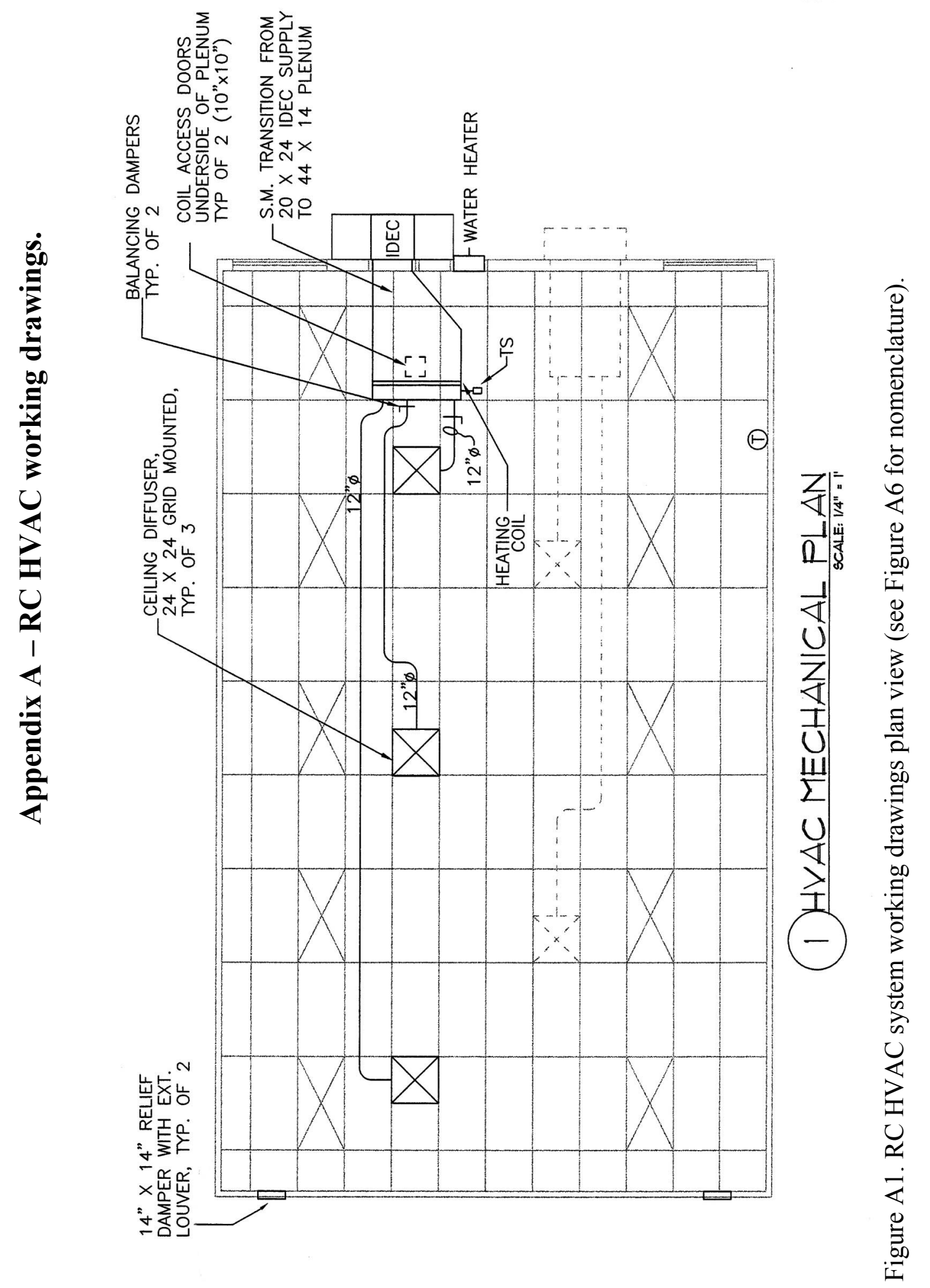




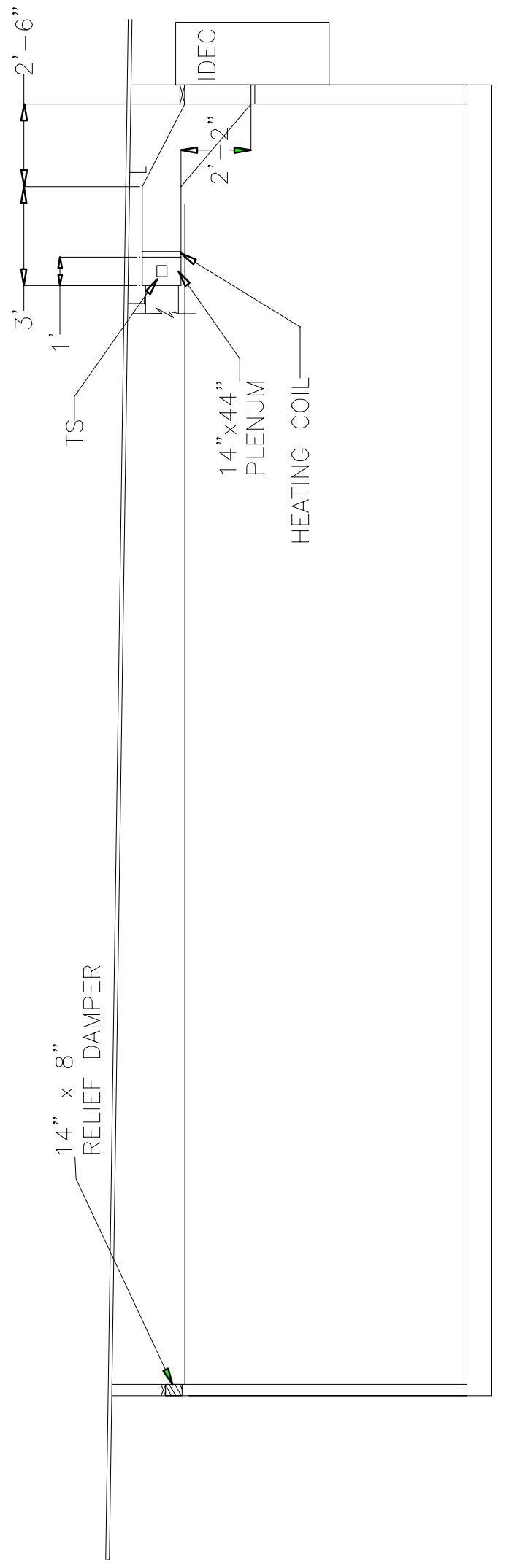

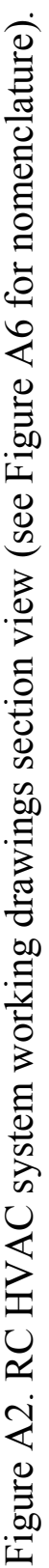



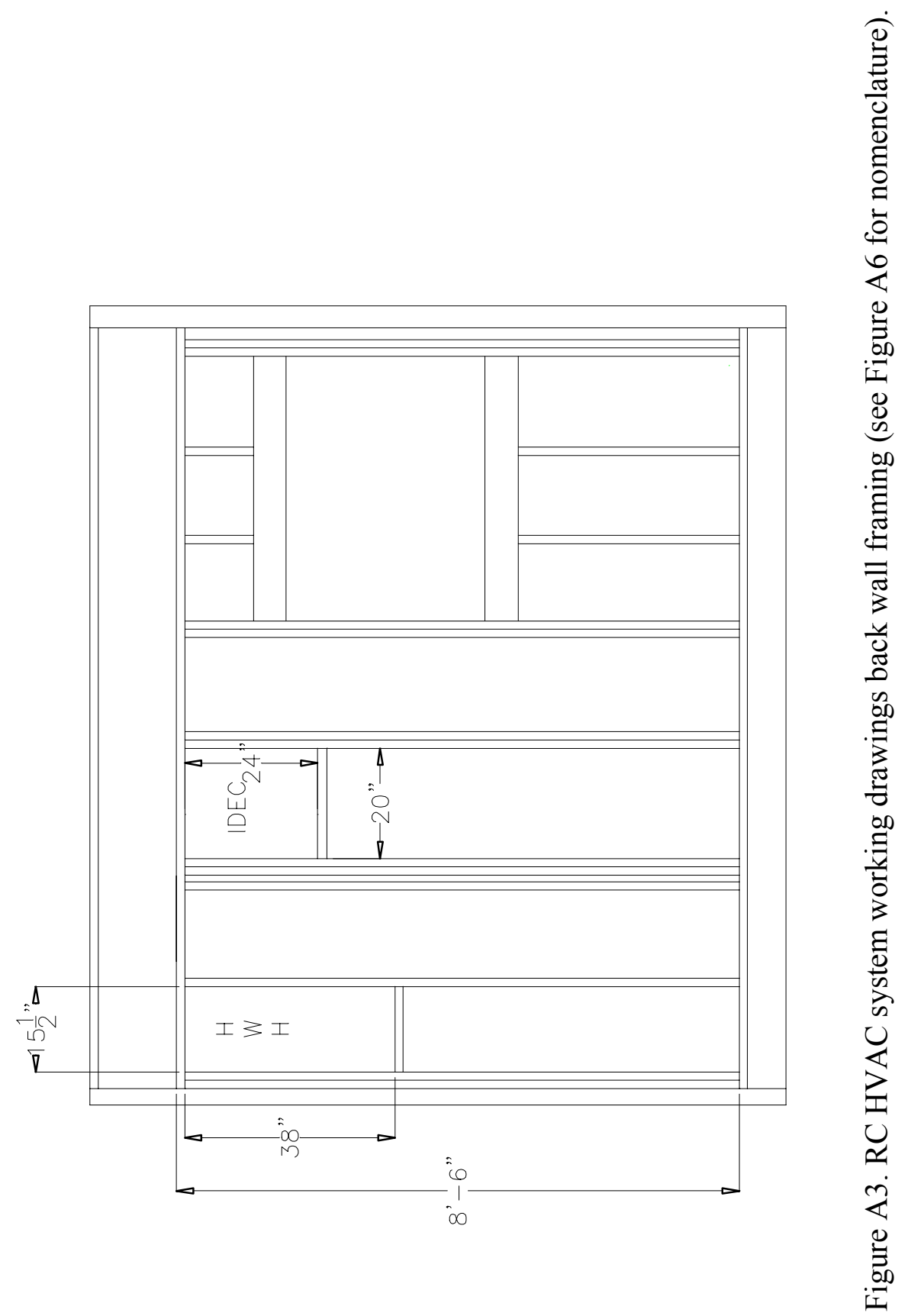


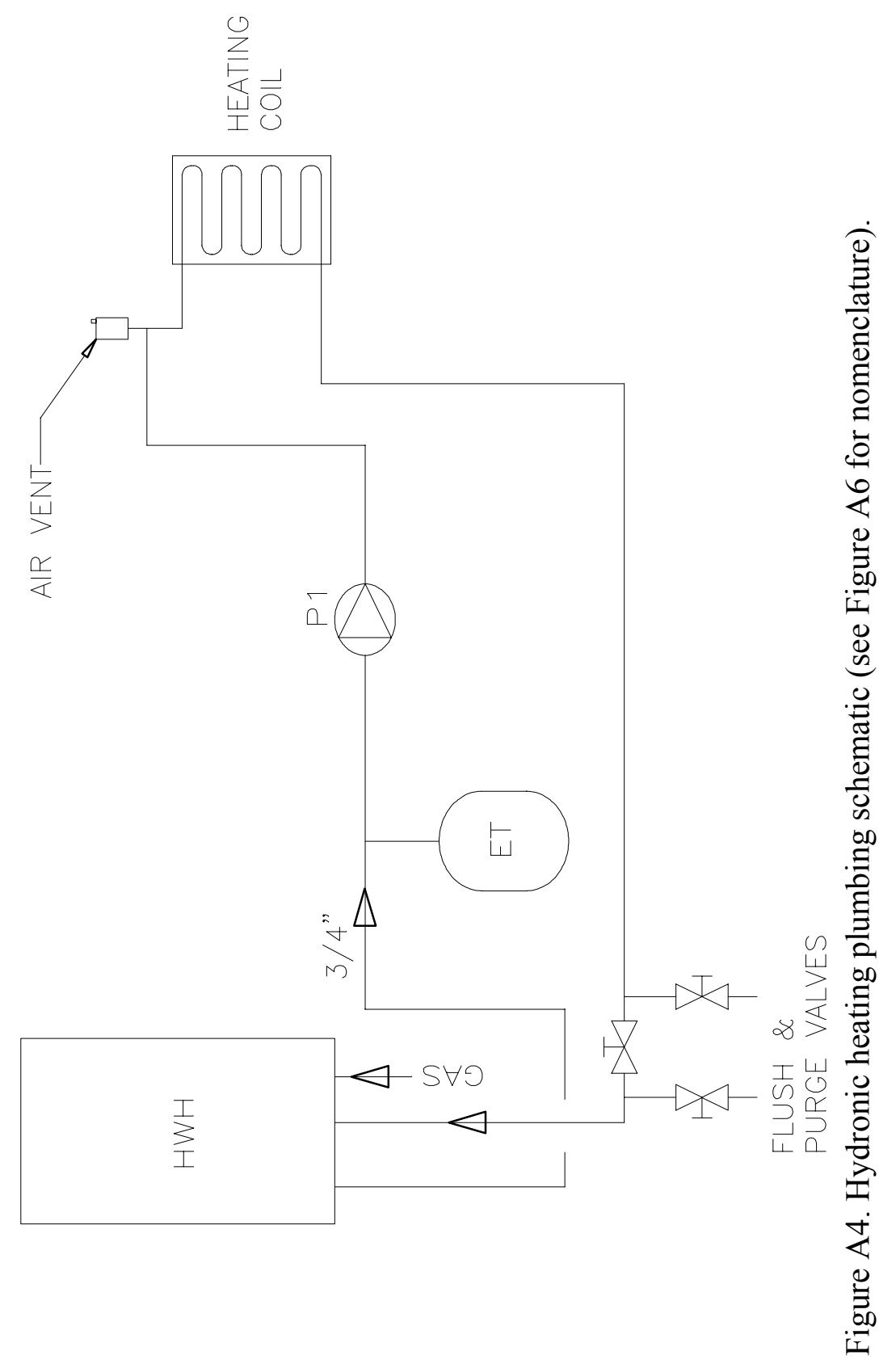




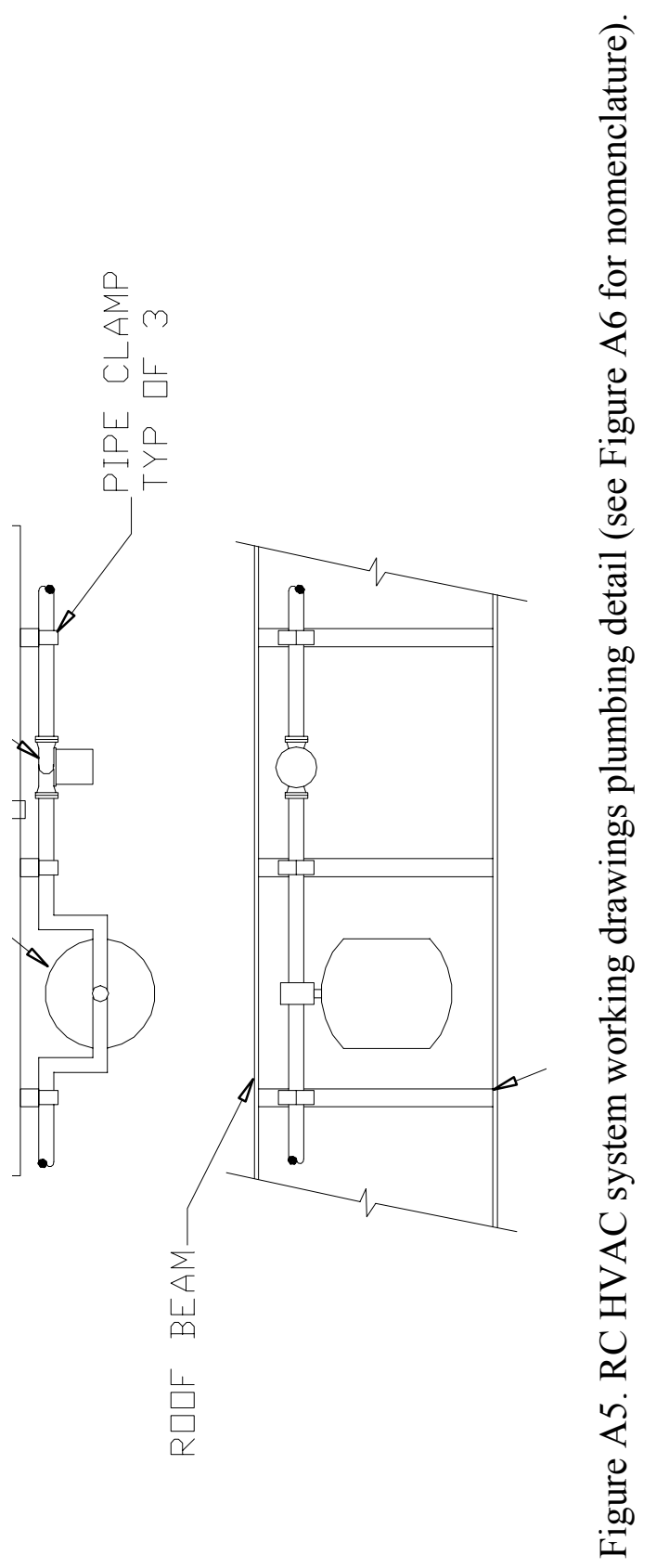




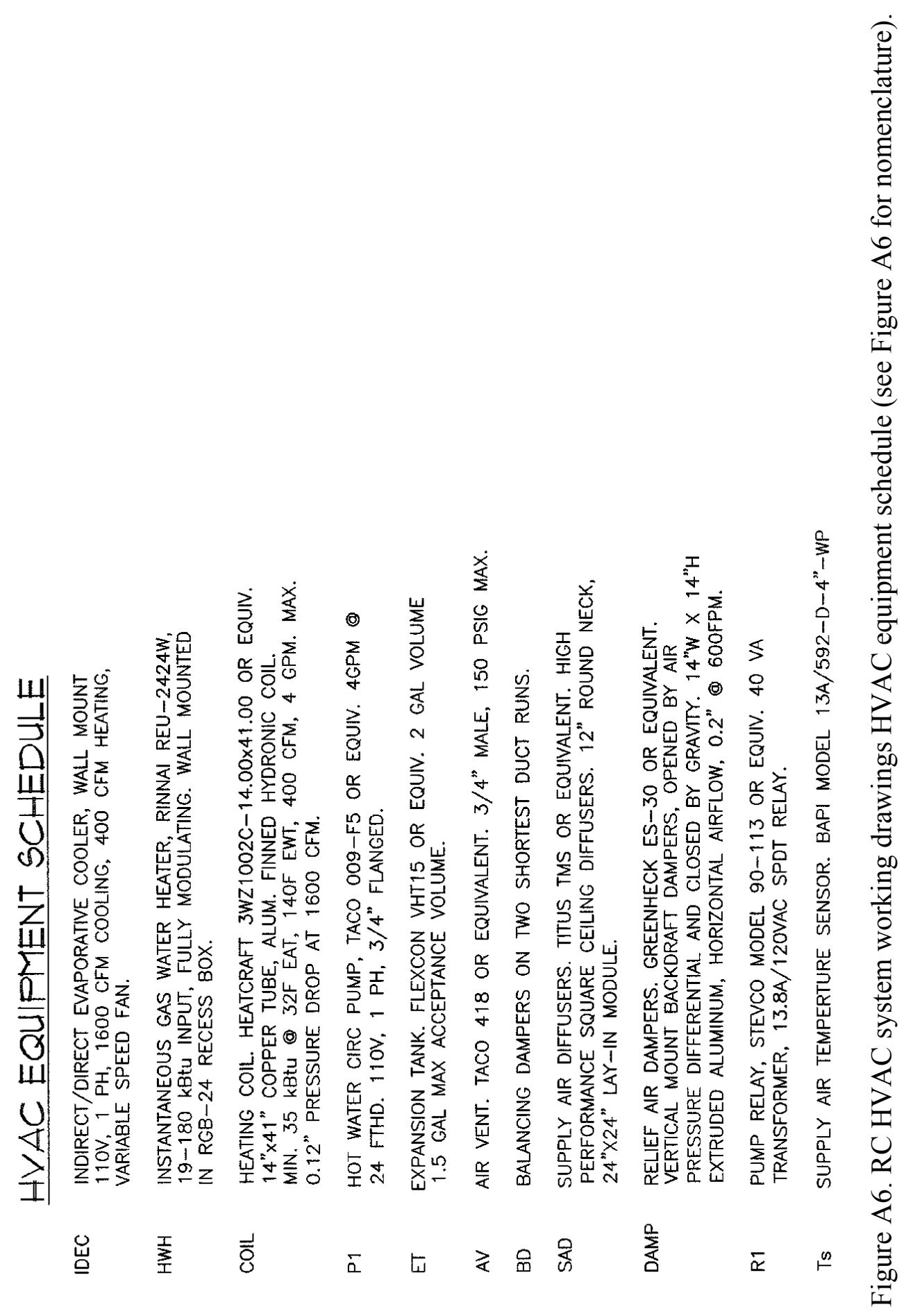




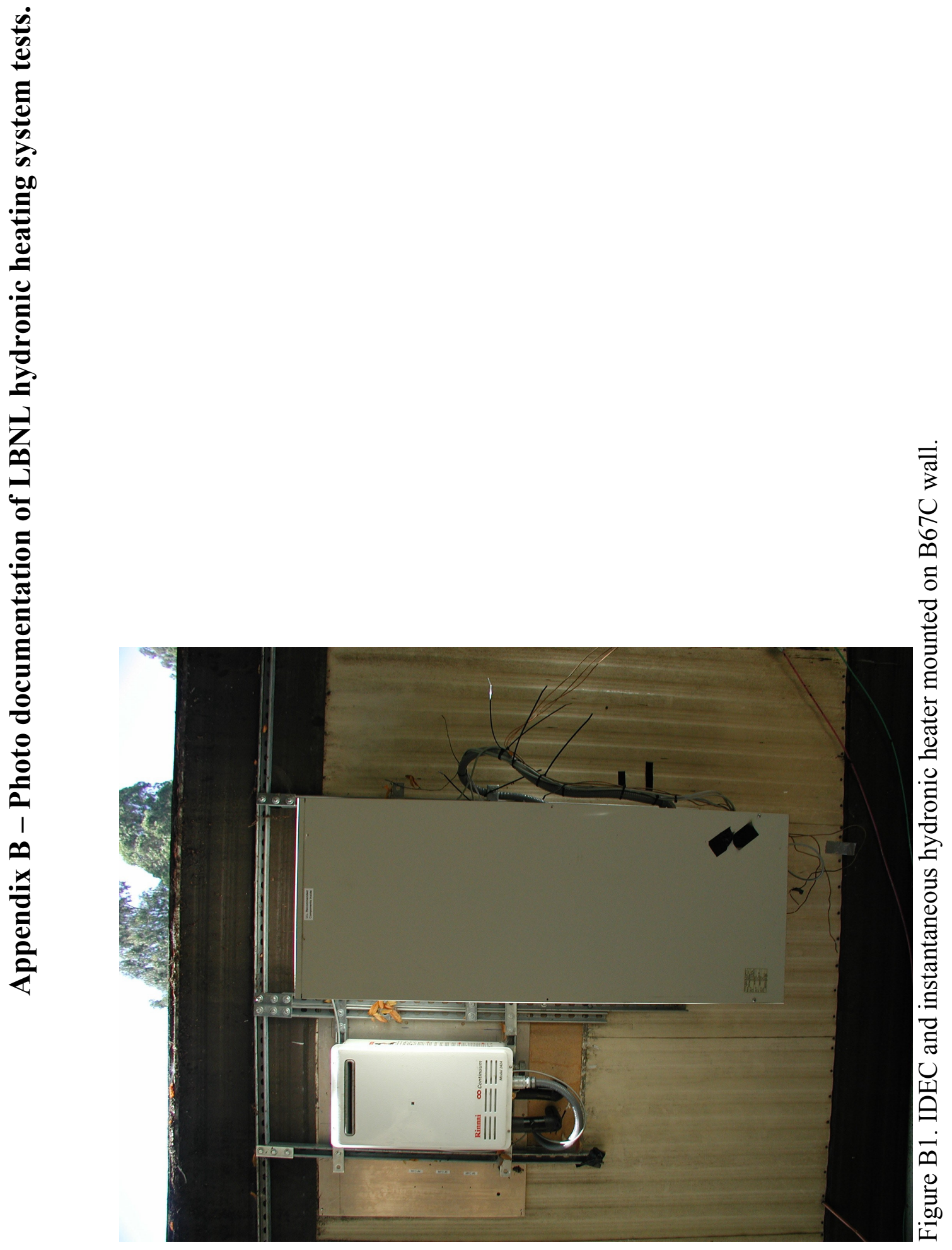




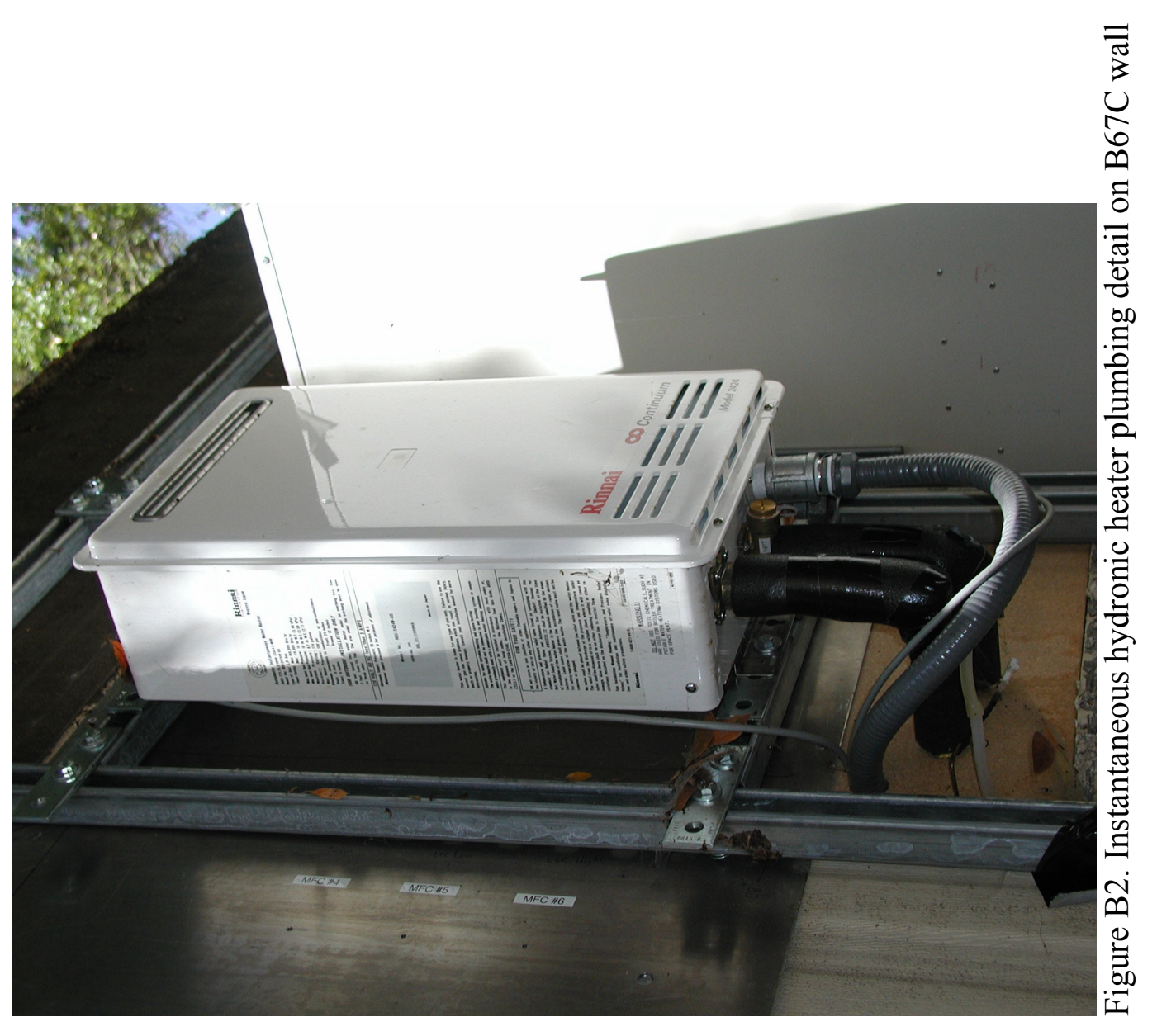

ก 


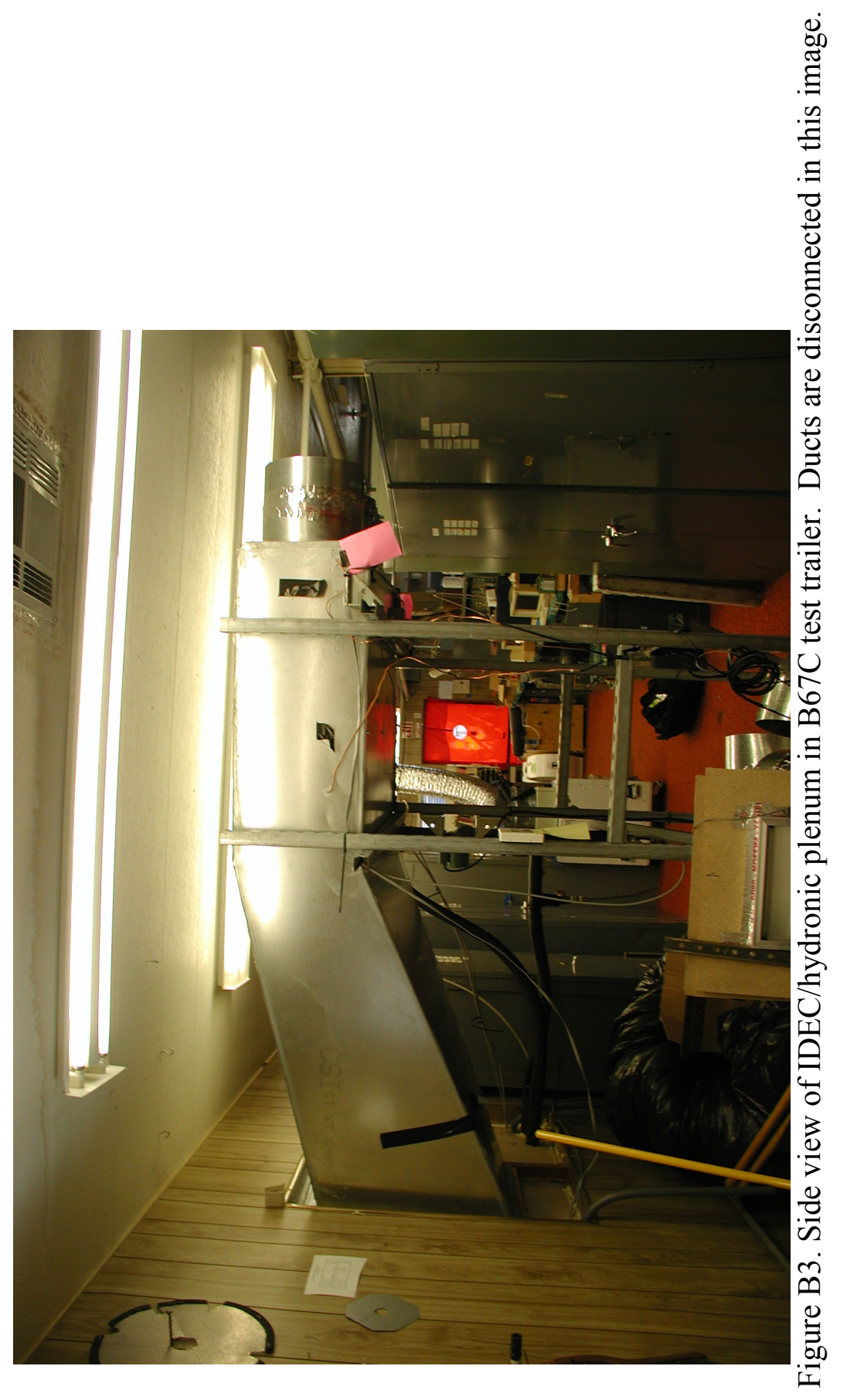

ติ 


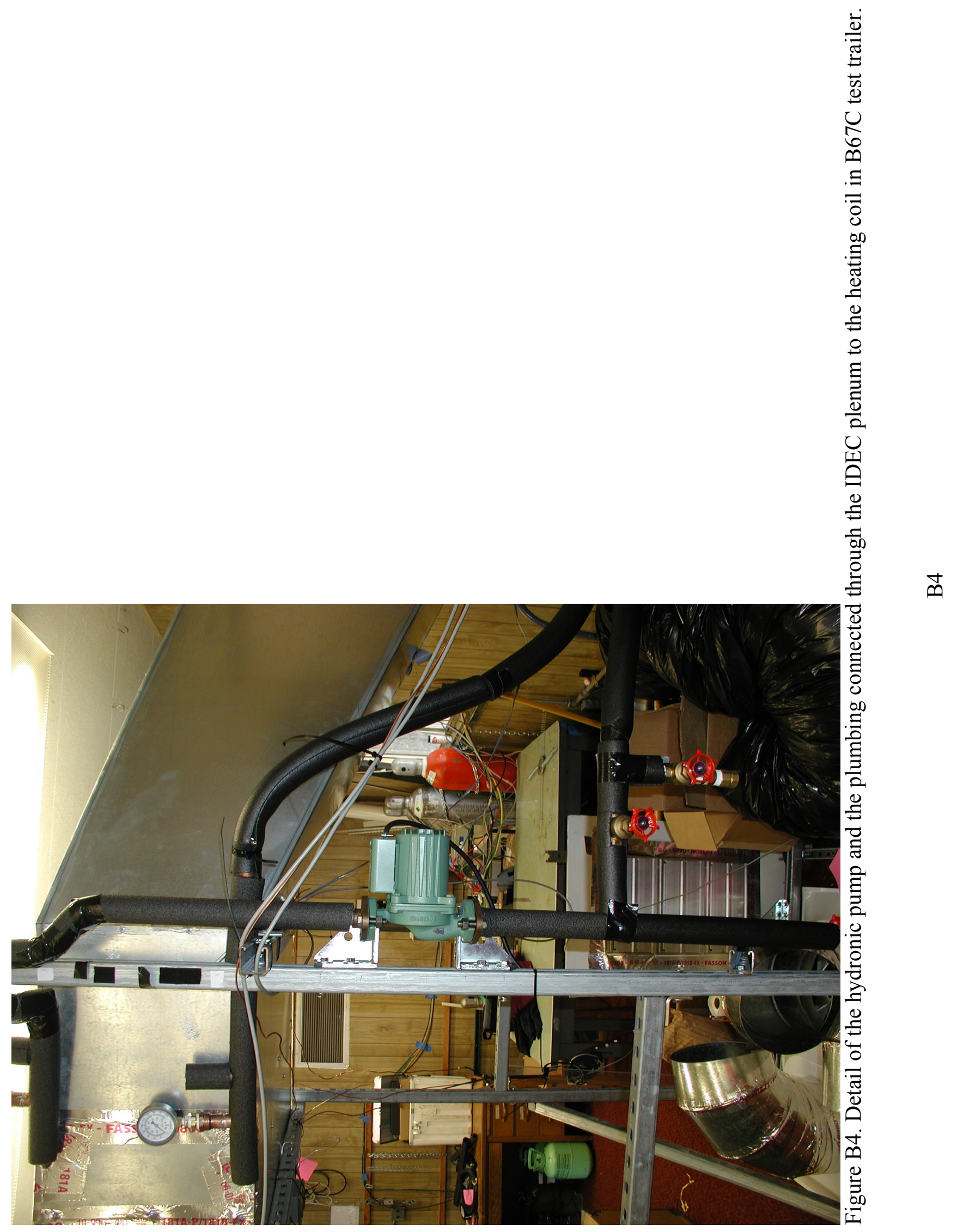




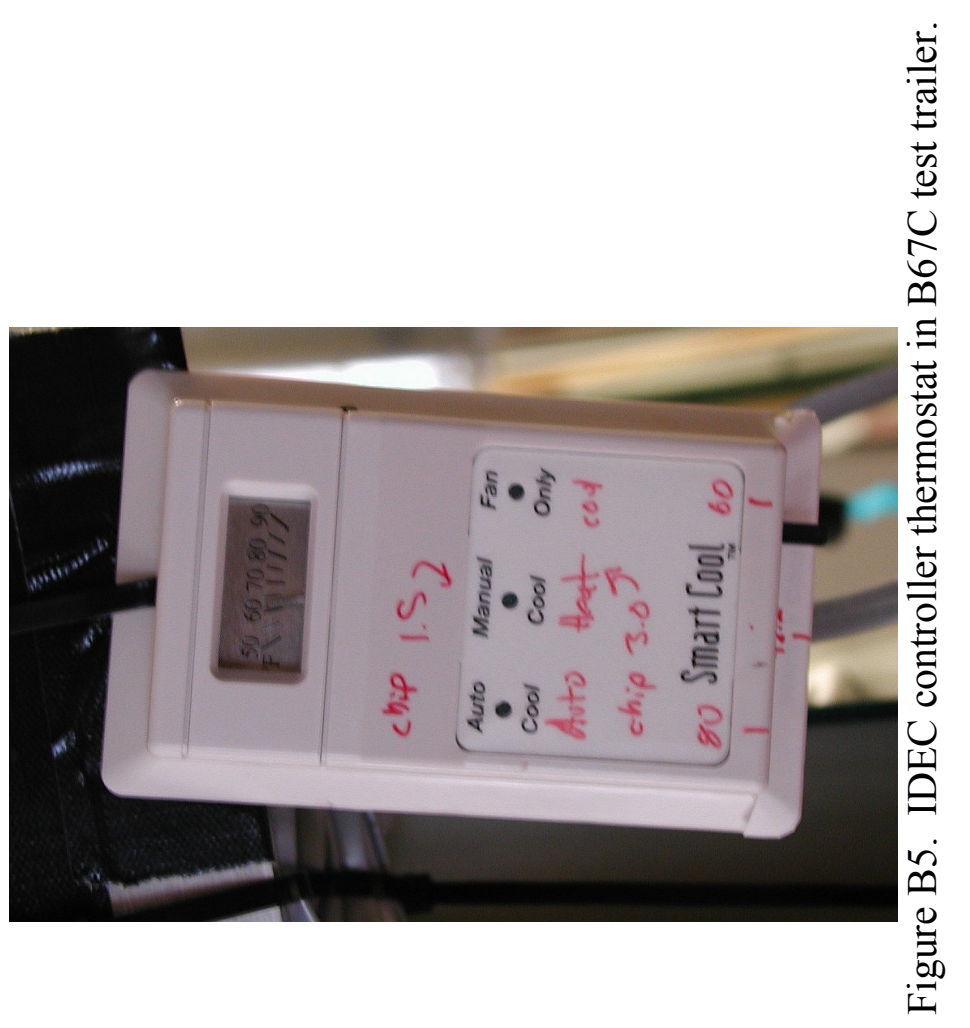




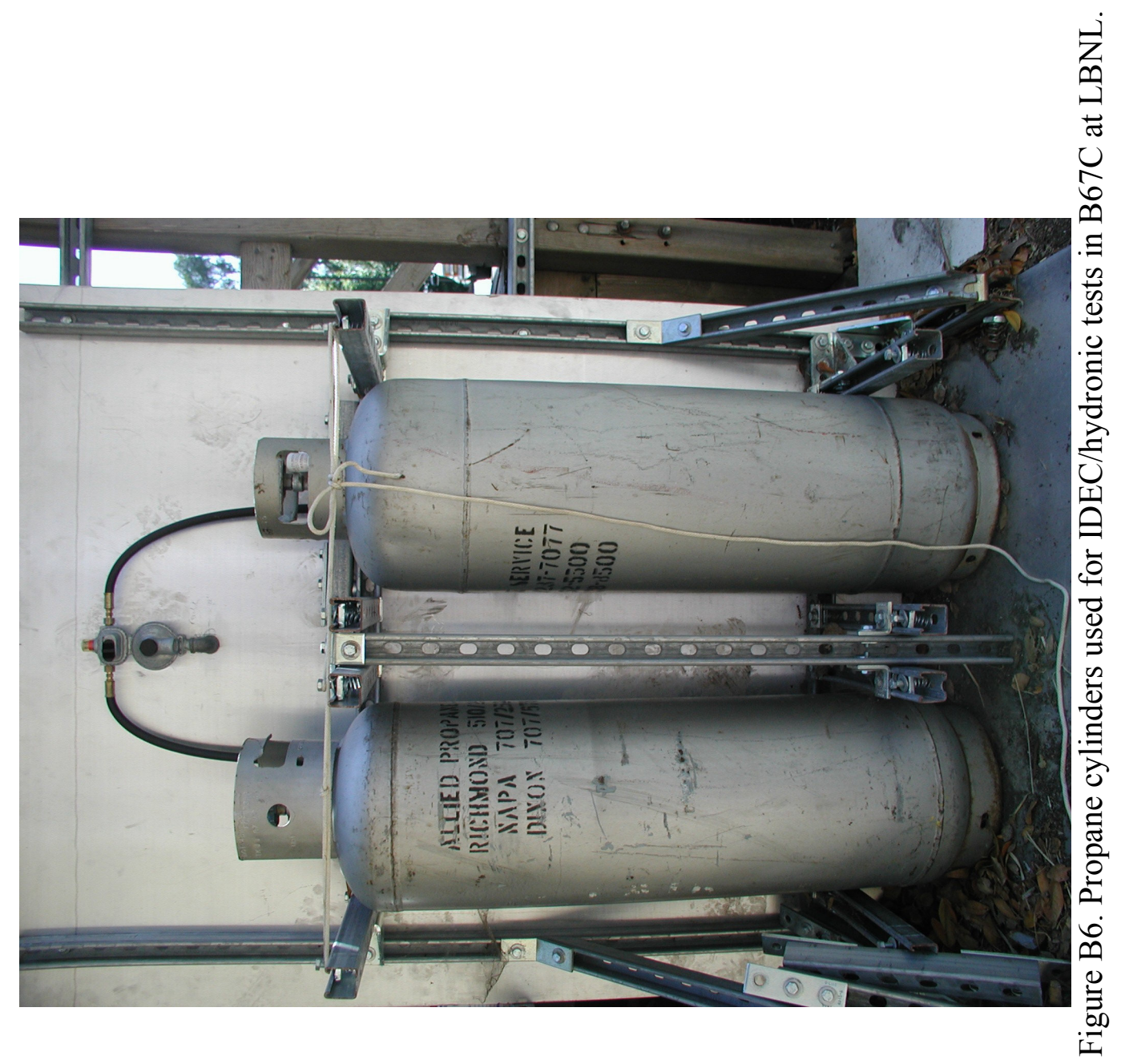

ஜ 